\title{
Oncogenic Virus Infections in the General Population and End-stage Renal Disease Patients With Special Emphasis on Kaposi's Sarcoma Associated Herpes Virus (KSHV) in Northeast of Iran
}

\author{
Sanaz Ahmadi Ghezeldasht ${ }^{1}$ Tahereh Hassannia ${ }^{2}$; Houshang Rafatpanah ${ }^{3}$; Reza Hekmat ${ }^{4}$; \\ Narges Valizadeh ${ }^{3}$; Majid Ghayour Mobarhan ${ }^{1}$; Seyed Abdolrahim Rezaee ${ }^{1,5,}$ \\ ${ }_{2}^{1}$ Research Center for HIV/AIDS, HTLV and Viral Hepatitis, Iranian Academic Center for Education, Culture and Research (ACECR), Mashhad Branch, Mashhad, IR Iran \\ ${ }_{3}^{2}$ Internal Medicine Department, Baharloo Hospital, Tehran University of Medical Sciences, Tehran, IR Iran \\ ${ }^{3}$ Immunology Research Center, Buali Research Institute, Mashhad University of Medical Sciences, Mashhad, IR Iran \\ ${ }_{5}^{4}$ Nephrology Department, Mashhad University of Medical Sciences, Mashhad, IR Iran \\ ${ }^{5}$ Inflammation and Inflammatory Diseases Research Center, Medical School, Mashhad University of Medical Sciences, Mashhad, IR Iran \\ ${ }^{*}$ Corresponding author: Seyed Abdolrahim Rezaee, Inflammation and Inflammatory Diseases Research Center, Medical School, Mashhad University of Medical Sciences, Mashhad, \\ IR Iran. Tel: +98-5138436626, E-mail: rezaeer@mums.ac.ir
}

Received: September 19,2013; Revised: December 14, 2013; Accepted: July 6, 2014

\begin{abstract}
Background: Globally, almost $20 \%$ of cancers are related to infectious agents that can be prevented. Oncogenicity refers to viruses that may cause cancers, more importantly in immunocompromised subjects such as transplant and hemodialysis patients. Therefore, epidemiological studies are the first line for understanding the importance of these agents in public health, particularly, in mobile populations, tourism and pilgrimage regions.

Objectives: Oncogenic viral infections, such as hepatitis B virus (HBV), hepatitis C virus (HCV) and Epstein-barr virus (EBV) are the most common viral agents in immunocompromised patients. Furthermore, human T lymphocyte virus type I (HTLV-I), due to endemicity in Khorasan Razavi province located northeast of Iran as a pilgrimage region, and Kaposi's sarcoma associated herpes virus (KSHV), as an oncogenic herpesvirus in immunocompromised subjects have been investigated among the general population and those with end-stage renal diseases (ESRD).

Patients and Methods: A cross-sectional study was carried out among 1227 randomly selected individuals; 25 donors and 195 patients with ESRD, including 60 kidney transplant recipients and 135 dialysis patients from the Khorasan Razavi province, Iran. Serological tests were carried out using commercial enzyme-immunoassay kits. To confirm positive serology tests, the extracted viral DNA or RNA was examined for the presence of KSHV, HTLV-I and HCV by conventional PCR.

Results: The prevalence of KSHV infection in the general population was 1.71\% (21/1227); 2.60\% (10/384) males and 1.30\% (11/843) females. In kidney transplants, viral infections occurred in $23.3 \%$ of subjects; including EBV, HTLV-I and HBV-HCV co-infection in $8.3 \%, 3.3 \%$ and $1.7 \%$, respectively. In patients on hemodialysis, viral infections were present in $29.6 \%$ including EBV, HTLV-I and HBV-HCV co-infection in $2.2 \%$, $5.9 \%$ and $16.3 \%$, respectively. Seroprevalence of KSHV in patients with kidney transplants was $1.7 \%$ and in patients on dialysis was $3.0 \%$. Furthermore, KSHV and HTLV-I genome was detected in $25 \%$ and $100 \%$ of seropositive subjects, respectively.

Conclusions: In conclusion, this study demonstrated that these tumor virus infections including HTLV-I, KSHV and particularly hepatitis viruses (HBV plus HCV) are prevalent in the general population and in patients on hemodialysis, which might be an important health concern in this region due to the mobile population.
\end{abstract}

Keywords: Oncogenic Viruses; HTLV-I Infections; Human Herpesvirus 8; Human Kidney Transplantation; HIV Seroprevalence; Kidney Failure; Chronic

\section{Background}

Cancer is the leading cause of death in developed countries and is the second cause of death in developing countries. According to international agency reports on cancer, it is estimated for the incidence of cancer to continue rising and cause 13.1 million deaths by 2030 (1). Some cancers can be caused in humans by viruses such as Kaposi's sarcoma associated herpes virus (KSHV), Epstein-barr virus (EBV), human T lymphocyte virus type I (HTLV-I), hepatitis B virus (HBV) and hepatitis C virus $(\mathrm{HCV})(2,3)$.

Herpesviruses have evolved strategies to evade immune control mechanisms in replication and latency phases for establishing infection and dissemination in host immunocompromised patients. In this family of viruses KSHV and EBV are known as tumor viruses (4). In the general population, Kaposi's sarcoma (KS) is a rare tumor; however, the risk of cancer development is substantially increased in immunocompromised patients including patients with acquired immunodeficiency syndrome (AIDS) and solid organ recipients (5). The incidence of iatrogenic KS that develops after organ transplantation,

Copyright (C) 2015, Ahvaz Jundishapur University of Medical Sciences. This is an open-access article distributed under the terms of the Creative Commons Attribution-NonCommercial 4.0 International License (http://creativecommons.org/licenses/by-nc/4.0/) which permits copy and redistribute the material just in noncommercial usages, provided the original work is properly cited. 
Ahmadi Ghezeldasht S et al.

is 500 times higher than the general population (6). Kaposi's sarcoma associated herpes virus or human herpesvirus 8 (HHV-8), a member of the Gammaherpesvirinae subfamily, is the etiological agent of KS. It may also cause primary effusion lymphoma (PEL) and multicentric Castleman's disease (MCD) (7). The prevalence of KSHV varies in the adult population, from less than $5 \%$ in the USA and Northern Europe to more than $50 \%$ in some regions of the African continent, and around $10 \%$ to $20 \%$ in Italy and Greece (8).

Post-transplant or iatrogenic KS has been found among recipients of solid organ transplants who are being treated with immunosuppressive medications (9). Moreover, KSHV has recently been linked to non-neoplastic manifestations such as hemophagocytic syndrome and cytopenia in renal graft recipients and acute bone marrow failure (8). The closest human relative of KSHV in gammaherpesviruses is EBV, which has been recognized as the etiological agent of nasopharyngeal carcinoma, Burkitt's lymphoma and Hodgkin's disease and post-transplant lymphoproliferative diseases (PLTD) in allograft recipients $(10,11)$.

Hepatitis B virus and HCV are the causative agents of chronic liver disease and it has been suggested that hepatocellular carcinoma (HCC) is among the top ten causes of death worldwide $(12,13)$. Furthermore, patients with chronic renal failure, notably those receiving hemodialysis, may be at increased risk of both HBV and HCV. Consequently, all non-immune patients with chronic renal failure should be vaccinated with HBV vaccine and immunity is established with HBV surface antibody screening following completion of the vaccination (14). Similar to HBV, HCV is a complex problem for renal transplant recipients. Incidence rates in the hemodialysis population have decreased, averaging $0.7 \%$ to $3 \%$ per year (15). Furthermore, HTLV-I belongs to the Retroviridae family and is associated with adult T-cell leukemia (ATL) (16) and the inflammatory condition of HTLV-I-associated myelopathy/ tropical spastic paraparesis (HAM/TSP) (17). However, the possible influence of an immunosuppressant on development of this disease has been controversial. The Khorasan Razavi province (located northeast of Iran), with a population of around 5.5 million according to the 2006 census, has been recognized as an endemic area for HTLVI infection since 1996 . Over two percent (2.12\%) of Mashhad residents, capital city of the Khorasan province, are HTLV-I carriers $(17,18)$.

These viruses are important from two aspects: firstly, since curable medications or vaccines for preventing KSHV, HCV and HTLV-I infections has still not been introduced, the prevalence of these viruses in pilgrimage regions such as Khorasan Razavi province should be evaluated. Secondly, these viruses and their co-infection with other tumorviruses are very important in immunocompromised subjects, a subject that has not been fully investigated thus far. Therefore, further studies should be conducted on the context of other infections for these agents, particularly, in allograft recipients and patients on hemodialysis (19).

\section{Objectives}

In the present study, the prevalence of KSHV and HTLV-I, also KSHV co-infection with HBV and HCV, were investigated in the general population and three high risk groups including kidney allograft transplant donors and recipients, and patients with end stage renal disease (ESRD), who are in the waiting list for transplantation. In our previous studies, the seroprevalence of HTLV-I (17), HBV (20) and HCV (unpublished data) in the general population was evaluated and the main findings are reported here.

\section{Patients and Methods}

\subsection{Study Population and Sample Size}

A cross-sectional study was conducted from February 2009 to May 2010 at Mashhad University of Medical Sciences (MUMS). The study was approved by MUMS ethical committee (No: 85949). The subjects from the general population were selected randomly by multistage sampling methods (stratified, cluster and systematic) from all 12 municipal areas. We selected one person from each household and tried to include equal ratios of both sexes as well as ten percentiles for age according to the 2006 census in each district. The presence of tumor viruses in 25 transplant donors and 195 patients (ESRD) including 60 kidney transplant subjects and 135 patients on hemodialysis waiting for transplantation were investigated. Whole blood samples were collected after obtaining an informed consent from each participant and sera were stored at $-20^{\circ} \mathrm{C}$. Demographic data such as gender, age and hemodialysis duration also were collected.

\subsection{Sample Collection and Serological Assay}

After obtaining an informed consent, $5 \mathrm{ml}$ brachial vein blood sample was collected from each of the participants in EDTA containing sterile tubes. Serum and peripheral blood mononuclear cell (PBMCs) samples were kept at $-20^{\circ} \mathrm{C}$ until analysis. Sera were tested for the presence of anti-KSHV (Biotrin, Ireland), anti-HTLV-I (Dia.pro, Italy), anti-HCV (Dia. pro, Italy), anti-EBV antibodies (IBL, Germany) and the surface antigen of HBV and HBsAg, (Radim, Italy) by enzyme-linked immunosorbent assay (ELISA) kits according to the manufacturers' instructions. White blood cell count and blood group were examined in 25 transplant donors and 195 patients with ESRD.

\subsection{Polymerase Chain Reaction (PCR) Tests}

The positive specimens were further confirmed by PCR using specific primers for KSHV, HTLV-I (Tax and LTR) and $\mathrm{HCV}$. To investigate the presence of KSHV genome (active infection) in the sera of seropositive subjects, DNA was extracted using available commercial kits (DNA blood 
Ahmadi Ghezeldasht S et al.

mini kit, Qiagen, Germany) and was kept at $-20^{\circ} \mathrm{C}$ and then PCR was carried out as previously described (7). Furthermore, HTLV-I provirus in seropositive subjects was detected by conventional PCR on PBMCs extracted DNA for Tax and long terminal repeat (LTR) regions (17). Hepatitis $C$ virus infection was confirmed by nested-RT-PCR. Extraction of RNA was performed by commercial kits (viral RNA mini kit, Qiagen, Germany). The HCV RNA was then reverse transcribed using a Revert Aid TM H minus First Strand cDNA Synthesis kit (Fermentas, Germany). Reverse transcription (RT) was carried out at $42^{\circ} \mathrm{C}$ for 60 minutes followed by RT inactivation at $70^{\circ} \mathrm{C}$ for five minutes. The cDNA was kept at $-20^{\circ} \mathrm{C}$ until use in HCV nested PCR according to the following protocol: $25 \mu \mathrm{L}$ reaction of $10 x$ buffer, $\operatorname{MgCl}_{2}(1.5 \mathrm{mM})$, dNTPs $(200 \mu \mathrm{M}), 10 \mathrm{pm}$ of each primers, $0.5-\mathrm{U}$ of Taq DNA polymerase and $3 \mu \mathrm{L}$ of cDNA. The HBV PCR amplification was carried out in a tube containing $25 \mu \mathrm{L}$ reaction of $10 \mathrm{x}$ buffer, $\mathrm{MgCl}_{2}(2$ $\mathrm{mM})$, dNTPs $(200 \mu \mathrm{M}), 10 \mathrm{pm}$ of each primer, 0.5 -U of Taq DNA polymerase and 100 ng DNA; the PCR condition was as follow; $94^{\circ} \mathrm{C}$ for three minutes and 20 cycles for first run, 30 cycles for second run $94^{\circ} \mathrm{C}$ for 40 seconds, $58^{\circ} \mathrm{C}$ for 40 seconds, $72^{\circ} \mathrm{C}$ for 40 seconds and final extension at $72^{\circ} \mathrm{C}$ for five minutes. Table 1 shows the sequence of primers for PCR.

\subsection{Statistical Analysis}

Data were analyzed using the SPSS software version 11.0 (SPSS Incorporated, Chicago, IL, USA). The analyses were carried out using descriptive statistical indexes including standard deviation, mean and confidence interval at 95\%. The differences were statistically analyzed by student T test. P values of $<0.05$ were considered statistically significant.

\section{Results}

4.1. Seroprevalence of Kaposi's Sarcoma Associated Herpes Virus, Human T Lymphocyte Virus Type I, Hepatitis $B$ Virus and Hepatitis C Virus in the General Population
The presence of KSHV antibody was evaluated in a total of 1227 participants from the general population. Amongst these participants, 384 (31.29\%) were male and $843(68.71 \%)$ were female. The overall seroprevalence of KSHV in this population was $1.71 \%$ ( $21 / 1227)$. Our findings indicated that $2.60 \%(10 / 384)$ of males and $1.30 \%(11 / 843)$ of females were KSHV positive and no statistical significance was observed between the two groups $(P=0.1)$. The overall prevalence of HBsAg positivity was $1.39 \%, 2.0 \%$ and $0.89 \%$ among men and women, respectively, with differences not being statistically significant $(P=0.054)(20)$. However, HCV was detected in approximately $0.6 \%$ of apparently healthy subjects; six of the infected cases (86\%) were male and only one female patient (14\%) was infected with HCV. The overall prevalence of HTLV-I infection in the entire population was $2.12 \%$ with no significant difference between males and females $(P=0.093)(17)$ (Table 2).

\subsection{Demographic and Laboratory Information of Donors and Patients with End Stage Renal Disease}

White blood count, ABO blood groups, viral infections and hemodialysis duration were evaluated in all three groups including healthy allograft kidney donors, allograft kidney recipients and subjects on hemodialysis. Demographic data and laboratory findings for these groups are shown in Table 3. There were no significant differences between prevalence of these viruses and the corresponding details such as WBC count, blood group and hemodialysis duration, as summarized in Table 3.

Table 1. The Nucleotide Sequence of Primers for Each PCR Protocol ${ }^{\mathrm{a}}$

\begin{tabular}{lc}
\hline Nucleotide position & Sequence $\left(\mathbf{5}^{\prime} \mathbf{3}^{\prime}\right.$ ) \\
\hline HCV f1 & CATAGATCACTCCCCTGTGAGG \\
HCV r1 & GGCGGTTGGTGTTACGTTTGGT \\
HCV f2 & CCCTGTGAGGAACTACTGTCTTC \\
HCV r2 & GGTGCACGGTTACGAGACCTC \\
\hline
\end{tabular}

a Abbreviations: $\mathrm{HCV}$; hepatitis $\mathrm{C}$ virus, f; forward; r; reverse.

Table 2. Viral Infections Among the General Population, Donors and Patients with End Stage Renal Disease ${ }^{\text {a }}$

\begin{tabular}{lcccc}
\hline Viral Infections & $\begin{array}{c}\text { General Population } \\
(\mathbf{n}=\mathbf{1 2 2 7})\end{array}$ & $\begin{array}{c}\text { Kidney Donors } \\
(\mathbf{n}=\mathbf{2 5})\end{array}$ & $\begin{array}{c}\text { Renal Transplant Recipi- Patients on Hemodialy- } \\
\text { ents }(\mathbf{n}=\mathbf{6 0})\end{array}$ & $\begin{array}{c}\text { sis }(\mathbf{n}=\mathbf{1 3 5}) \\
\text { Negative for studied virus }\end{array}$ \\
\hline HTLV-I & 2.12 & $100^{\mathrm{b}}$ & 76.7 & 70.4 \\
EBV & No data & 0 & 3.3 & 5.9 \\
KSHV & 1.71 & 0 & 8.3 & 2.2 \\
HBV + HCV & 2 & 0 & 1.7 & 3.0 \\
\hline
\end{tabular}

\footnotetext{
a Abbreviations: EBV, Epstein-barr virus; HTLV-I, human T lymphocyte virus type I; HBV, hepatitis B virus; HCV, hepatitis C virus; KSHV, Kaposi's sarcoma associated herpes virus.

b Data are presented as (\%).
} 
Ahmadi Ghezeldasht S et al.

\begin{tabular}{|c|c|c|c|}
\hline & Kidney Donors $(\mathbf{n}=25)$ & Renal Transplant Recipients $(n=60)$ & Patients on Hemodialysis $(n=135)$ \\
\hline \multicolumn{4}{|l|}{ Men } \\
\hline Sample Size & $17(68)$ & $37(61.7)$ & $67(49.6)$ \\
\hline Age, y & $37.82 \pm 7.30$ & $36.70 \pm 15.3$ & $43.52 \pm 12.45$ \\
\hline WBC Count & $7876.47 \pm 1341.88$ & $11789.18 \pm 3756.45$ & $7422.37 \pm 2114.98$ \\
\hline \multicolumn{4}{|l|}{ Women } \\
\hline Sample Size & $8(32)$ & $23(38.3)$ & $68(50.4)$ \\
\hline Age, y & $37.87 \pm 2.99$ & $34.84 \pm 13.54$ & $50.50 \pm 13.19$ \\
\hline WBC Count & $8318.75 \pm 1992.83$ & $11408.65 \pm 4481.16$ & $2825.51 \pm 7052.88$ \\
\hline \multicolumn{4}{|l|}{ Blood Group } \\
\hline A & $6(24)$ & $14(23.3)$ & $28(20.7)$ \\
\hline B & $11(44)$ & $26(43.3)$ & $76(56.3)$ \\
\hline $\mathrm{AB}$ & $3(12)$ & $10(16.7)$ & $11(8.1)$ \\
\hline $\mathrm{O}$ & $5(20)$ & $10(16.7)$ & $20(14.8)$ \\
\hline Hemodialysis duration & No Data & $11.63 \pm 7.37$ & $7 \pm 3.8$ \\
\hline
\end{tabular}

\subsection{Viral Infections Among Donors and Patients With End Stage Renal Disease}

Viral infections such as KSHV, EBV, HTLV-I, HBV and HCV were not detected, in healthy allograft kidney donors due to robust examination for donor selection. In allograft kidney transplant patients, viral infections were present 23.3\%; 8.3\% EBV, 3.3\% HTLV-I, 1.7\% KSHV and 1.7\% HBV-HCV co-infection. Occurrence of viral infections in subjects on hemodialysis was $29.6 \%$, including $16.3 \%$ HBV-HCV coinfection, 5.9\% HTLV-I, 3\% KSHV and 2.2\% EBV (Table 2).

\subsection{Kaposi's Sarcoma Associated Herpes Virus In- fection in Patients With End Stage Renal Disease}

The seroprevalence of KSHV in subjects on hemodialysis and allograft kidney recipients was 3\% (4/135) and $1.7 \%$ (1/60), respectively. Taken together, the prevalence of KSHV among patients with ESRD was 2.6\% (5/195). We could not find any significant correlation between gender, WBC count, dialysis duration and KSHV infection in renal transplant recipients (Table 4). There was a significant correlation in the hemodialysis group between KSHV infection and gender $(\mathrm{P}=0.044)$. There was no correlation between KSHV infection and age, WBC count or dialysis duration $(\mathrm{P}>0.05)$ (Table 5$)$.

The patients on dialysis and kidney recipients together can be studied as an end stage renal disease group, thus 195 patients with ESRD were entered in the present study, of which KSHV infection was found in five patients (2.5\%). However, we could not find any significant correlation between age, gender, WBC count and hemodialysis duration with KSHV infection in subjects with ESRD (Table 6). To evaluate if patients have active infection, a DNA PCR test was carried out on purified DNA from plasma of positive subjects. The results showed that there was no active KSHV infection among KSHV seropositive kidney recipients. However, one of the KSHV seropositive subjects with high level of specific anti KSHV IgG in the hemodialysis group had a positive PCR test.

\begin{tabular}{lcc}
\hline Table 4. Renal Transplant Recipients a,b & \\
\hline Variables & $\begin{array}{c}\text { KS Positive } \\
(\mathbf{n}=\mathbf{1})\end{array}$ & $\begin{array}{c}\text { KS Negative } \\
(\mathbf{n}=\mathbf{5 9})\end{array}$ \\
\hline Gender & $1(1.7)$ & $36(98.3)$ \\
Male $(\mathrm{n}=37)$ & 0 & $23(100)$ \\
Female $(\mathrm{n}=23)$ & 12800.0 & $11623.71 \pm 4048.13$ \\
WBC Count & 8.00 & $11.74 \pm 7.42$ \\
\hline Hemodialysis duration &
\end{tabular}

a Abbreviations: KS, Kaposi's Sarcoma; WBC, white blood cells.

$\mathrm{b}$ Data are presented as mean \pm SD, mean or No. (\%).

Table 5. Patient on Hemodialysis a,b

\begin{tabular}{lcc}
\hline Variables & $\begin{array}{c}\text { KS Positive } \\
(\mathbf{n}=\mathbf{4})\end{array}$ & $\begin{array}{c}\text { KS Negative } \\
(\mathbf{n}=\mathbf{1 3 1})\end{array}$ \\
\hline Age & $45.50 \pm 14.15$ & $47.08 \pm 13.27$ \\
Gender & & \\
\multicolumn{1}{c}{ Male $(\mathrm{n}=67)$} & 0 & $67(100)$ \\
Female $(\mathrm{n}=68)$ & $4(6)$ & $64(94)$ \\
WBC & $6475.00 \pm 1875.05$ & $7259.50 \pm 2514.26$ \\
Hemodialysis Duration & $7.25 \pm 3.30$ & $7.06 \pm 3.29$ \\
\hline a Abbreviations: KS, Kaposi's Sarcoma; WBC, white blood cells. \\
b Data are presented as mean \pm SD or No. $(\%)$.
\end{tabular}


Ahmadi Ghezeldasht S et al.

Table 6. End Stage Renal Disease (Hemodialysis Patients and Transplant Recipients) ${ }^{\mathrm{a}, \mathrm{b}}$

\begin{tabular}{lcc}
\hline Variables & $\begin{array}{c}\text { KS Positive } \\
(\mathbf{n}=\mathbf{5})\end{array}$ & $\begin{array}{c}\text { KS Negative } \\
(\mathbf{n}=\mathbf{1 9 0})\end{array}$ \\
\hline Age & $44.60 \pm 12.42$ & $43.615 \pm 14.63$ \\
Gender & & \\
\multicolumn{1}{|c}{ Male $(\mathrm{n}=104)$} & $1(0.96)$ & $103(99.4)$ \\
\hline Female $(\mathrm{n}=91)$ & $4(4.3)$ & $87(95.7)$ \\
WBC Count & $7740.00 \pm 3261.59$ & $8614.70 \pm 3671.02$ \\
Hemodialysis Duration & $7.40 \pm 2.88$ & $8.51 \pm 5.39$ \\
\hline \multicolumn{2}{l}{ a Abbreviations: KS, Kaposi's Sarcoma; WBC, White blood cells. } \\
b Data are presented as mean \pm SD or No. $(\%)$. &
\end{tabular}

\section{Discussion}

Deaths from cancer worldwide are rising, with an estimated 13.1 million deaths in 2030, particularly in immunocompromised people (1). Human tumorviruses are associated with a variety of human malignancies, where around 15\% of human cancers are virus related. The substantial morbidity in solid organ transplants is due to chronic immunosuppressive therapy which is administered to prevent graft rejection. Cancer is a major adverse outcome of immunosuppressive therapy (21, 22). Risks are especially high for malignancies caused by viral infections, including non-Hodgkin lymphoma (NHL) and Hodgkin lymphoma (both due to EBV (23)), Kaposi sarcoma (human herpesvirus 8), anogenital cancers (human papillomavirus), liver cancer (HCV and HBV viruses) and ATL in endemic regions of HTLV-I (24).

The study of tumorviruses brings exciting challenges for understanding the mechanisms of virus pathogenesis, including those involved in host immune evasion and establishing infection, dissemination in the host and oncogenicity in immunocompromised subjects (19). One of these viral infections, which mostly occur in immunocompromised subjects, particularly allograft recipients, is KSHV. A strong association between KSHV and KS, and PEL and MCD has been evident in transplant recipients, particularly kidney recipients $(25,26)$. The incidence of KS related to Kaposi sarcoma-associated herpesvirus (KSHV/HHV-8) after organ transplantation is 500-1000 times greater than in the general population, and its occurrence is associated with immunosuppressive therapy. The reported incidence of post-transplant KS ranges from $0.5 \%$ to $5 \%$, depending on the patient's country of origin and the type of organ received, mainly after renal transplantation (27). In Iran, it is assumed that Kaposi's sarcoma is the most common malignancy following renal transplantation (28).

Some studies have reported that the prevalence of KSHV infection in kidney donors is less than the general population or the recipients (29). In the present study the seroprevalence of this virus was $1.71 \%$ in the general population (21/1227), $0 \%$ in donors (due to a tough monitoring protocol for choosing healthy live kidney donors of virus- es infection), $1.7 \%$ in kidney recipients and 3.0\% in patients on dialysis. Overall $2.5 \%$ of ESRD subjects were infected with KSHV. A study from central Iran demonstrated that the seroprevalence of KSHV was $16.9 \%, 25 \%$ and $45.7 \%$ in patients on hemodialysis, renal transplant recipients and patients with HIV, respectively compared to blood donors (2\%) (30). These data are much higher than our study in case of the general population and hemodialysis and kidney transplant patients. These variations might be due to various methodology or geographic differences between northeast and central Iran. On the other hand, the prevalence of KSHV in blood donors seems to be very high in this study, as it can be expected. The importance of KSHV in transplant recipients has been shown by several studies in endemic areas, where the risk of Kaposi's sarcoma has been 1-3\% (31), while in Saudi Arabia, the risk is about $3 \%$ to $5 \%$ of all recipients $(26,32)$. Therefore, in endemic regions, serological screening of donors for KSHV is as much important as in recipients (25).

It can be concluded that the prevalence of KSHV infection in patients undergoing dialysis is nearly two times more than renal transplant recipients and the general population, thus, KSHV infection should be taken into account in hemodialysis and kidney transplant recipients. The results of this study showed that there is no any correlation between KSHV infection and age and sex in patients with ESRD. In our study the prevalence of KSHV in males was higher than females (2.6\% vs. $1.3 \%)$. Other studies reported the same results; for instance in America, the incidence of KS and prevalence of KSHV in transplant patients was higher in men compared to women (33) and in Saudi Arabia the ratio of males to females was 15:1(34). Hepatocellular carcinoma (HCC) can be caused by chronic viral infection. World-wide, chronic viral hepatitis, due to either HBV or HCV, is the leading cause of HCC (35). Hepatitis B virus infection remains a principal cause of liver disease in renal transplant (RT) recipients and the outcome of HBV infected RT recipients is less beneficial than that of non-infected RT recipients (36). An elevated incidence of HCC might be expected in solid organ transplant recipients, given the high prevalence of HCV and HBV infection among this group $(37,38)$. Presently, it is estimated that the prevalence of HBV in the hemodialysis population ranges from $0.1 \%$ to $0.4 \%$ (39). Approximately in $2 \%$ to $10 \%$ of patients with a history of HBV before transplantation (prevalence of HBV in the general population in our region is $1.39 \%$ ), the infection will reactivate after transplantation. People infected with HCV, usually experience a marked rise in viral load with initiation of immunosuppression immediately after transplantation. Furthermore, patients with HCV are at increased risk for progressive liver disease and the development of cirrhosis following transplantation (39). Further studies may be helpful to determine the best possible management protocol for $\mathrm{HBV}$ and $\mathrm{C}$ following transplantation. It is important to note that withdrawal of antiviral therapy may result in an exacerbation of liver disease (39). 
The prevalence of HTLV-I infection in renal transplantation patients remains poorly defined and the possible influence of immunosuppression on the disease caused by HTLV-I is unclear (40). Mashhad, in northeast Iran, with high prevalence of infection $(2.12 \%)$ has a noticeable number of infected renal failure patients. Since immunosuppressive drugs might reduce the latency period of HTLV-I or increase its complications, it is not clear whether HTLV-I positive renal failure patients are suitable candidates for kidney transplantation. One study performed in Mashhad indicated that HTLV-I positive patients might undergo kidney transplantation without fear of increased incidence of side effects compared to uninfected recipients (36). In addition, another study from northwest of Iran showed that the frequency of HTLV-I in renal transplant recipients was low, and was comparable to HTLV-I seroprevalence among hemodialysis patients (41).

Diseases caused by the herpesvirus family are common, especially in immunocompromised subjects. Furthermore, the majority of symptomatic human herpesvirus 4 (EBV) infections in renal transplant recipients are primary infections, likely related to reactivation of virus donor (39). Kidney transplant subjects have the lowest risk of post-transplant lymphoproliferative disease (PTLD) in comparison with other transplant populations (approximately $1 \%$ to $3 \%$ ). Furthermore, PTLD most commonly occurs during the first year post transplantation (23). In the present study, due to the lack information regarding the prevalence of EBV prevalence in Khorasan Razavi province, we could not compare EBV infection between patients and the general population, so further studies are needed to examine the prevalence of EBV infection in the general population.

In conclusion, this study demonstrated that tumor virus infections, HTLV-I, KSHV and particularly hepatitis viruses (HBV plus HCV) are prevalent in the general population and are high in patients on hemodialysis, which may be an important health concern in this region. Effective programs to mitigate these risks should be undertaken in such areas. Health education, vaccination (HBV), regular testing, routine screening of infected immunocompromised subjects, control of high-risk behaviors and facilitation of access for treatment are essential to decrease the associated risks and prevent infection spread within the population. In case of HTLV-I and KSHV, the health authorities should consider these infections at the local and national level, to prevent virus transmission and spreading. Furthermore, the study of tumor viruses paves the way and encourages researchers to understand the mechanisms of virus pathogenesis, including those involved in establishing infection and dissemination in the host tumor affecting immune-compromised patients. Viral infection is usually not the only cause of cancer, as environmental and host factors may be implicated as well. Thus further studies from different regions of Iran are needed to define co-factors associated with viral infections and patient's risk groups.

\section{Acknowledgements}

We thank the Mashhad Branch of the Iranian Academic Center for Education, Culture and Research (ACECR), and the Mashhad University of Medical Sciences for their kind cooperation and assistance.

\section{Authors' Contributions}

Seyed Abdolrahim Rezaee: study concept and design, supervision and critical revision of the manuscript. Sanaz Ahmadi ghezeldasht: drafting of the manuscript and performing the tests. Tahereh Hassannia: visiting the patients, statistical analysis and interpretation of data. Houshang Rafatpanah and Reza Hekmat:visiting the subjects and sample collection. Narges Valizadeh: filling the questionnaire and performing the PCR tests. Majid Ghayour Mobarhan: granted the study, donated the serum and data for the general population.

\section{References}

1. Ferlay J, Shin HR, Bray F, Forman D, Mathers C, Parkin DM. Estimates of worldwide burden of cancer in 2008: GLOBOCAN 2008. Int J Cancer. 2010;127(12):2893-917.

2. Adjei AA, Armah HB, Gbagbo F, Ampofo WK, Boamah I, AduGyamfi C, et al. Correlates of HIV, HBV, HCV and syphilis infections among prison inmates and officers in Ghana: A national multicenter study. BMC Infect Dis. 2008;8:33.

3. Saha A, Kaul R, Murakami M, Robertson ES. Tumor viruses and cancer biology: Modulating signaling pathways for therapeutic intervention. Cancer Biol Ther. 2010;10(10):961-78.

4. Ahmadpoor P. Human herpesvirus-8 and Kaposi sarcoma after kidney transplantation: mechanisms of tumor genesis. Iran J Kidney Dis. 2009;3(3):121-6.

5. Allen UD. Human herpesvirus type 8 infections among solid organ transplant recipients. Pediatr Transplant. 2002;6(3):187-92.

6. Mendez JC, Paya CV. Kaposi's Sarcoma and Transplantation. Her pes. 2000;7(1):18-23.

7. Moore PS. The emergence of Kaposi's sarcoma-associated herpesvirus (human herpesvirus 8). N Engl J Med. 2000;343(19):1411-3.

8. Plancoulaine S, Gessain A. [Epidemiological aspects of human herpesvirus 8 infection and of Kaposi's sarcoma]. Med Mal Infect. 2005;35(5):314-21.

9. Hjalgrim H, Melbye M, Pukkala E, Langmark F, Frisch M, Dictor M et al. Epidemiology of Kaposi's sarcoma in the Nordic countries before the AIDS epidemic. BrJ Cancer. 1996;74(9):1499-502.

10. Fickenscher H, Fleckenstein B. Herpesvirus saimiri. Philos Trans $R$ Soc Lond B Biol Sci. 2001;356(1408):545-67.

11. Hanto DW. Classification of Epstein-Barr virus-associated posttransplant lymphoproliferative diseases: implications for understanding their pathogenesis and developing rational treatment strategies. Annu Rev Med. 1995;46:381-94.

12. Ott JJ, Stevens GA, Groeger J, Wiersma ST. Global epidemiology of hepatitis B virus infection: new estimates of age-specific HBsAg seroprevalence and endemicity. Vaccine. 2012;30(12):2212-9.

13. Ahmad B, Ali S, Ali I, Azam S, Bashir S. Response rates of standard interferon therapy in chronic HCV patients of Khyber Pakhtunkhwa (KPK). Virol J. 2012;9:18.

14. Recommendations for preventing transmission of infections among chronic hemodialysis patients. MMWR Recomm Rep. 2001;50(RR-05):1-43.

15. Green MAR, Preiksaitis J. Guidelines for the prevention and management of infectious complications of solid organ transplantation. Am J Transplant. 2004;4(10).

16. Ahmadi Ghezeldasht S, Shirdel A, Assarehzadegan MA, Hassannia T, Rahimi H, Miri R, et al. Human T Lymphotropic Virus Type I (HTLV-I) Oncogenesis: Molecular Aspects of Virus and Host In- 
teractions in Pathogenesis of Adult T cell Leukemia/Lymphoma (ATL). Iran J Basic Med Sci. 2013;16(3):179-95.

17. Rafatpanah H, Hedayati-Moghaddam MR, Fathimoghadam $F$, Bidkhori HR, Shamsian SK, Ahmadi S, et al. High prevalence of HTLV-I infection in Mashhad, Northeast Iran: a population-based seroepidemiology survey. J Clin Virol. 2011;52(3):172-6.

18. Azarpazhooh MR, Hasanpour K, Ghanbari M, Rezaee SA, Mashkani B, Hedayati-Moghaddam MR, et al. Human T-lymphotropic virus type 1 prevalence in northeastern Iran, Sabzevar: an epidemiologic-based study and phylogenetic analysis. AIDS Res Hum Retroviruses. 2012;28(9):1095-101.

19. Rezaee SA, Cunningham C, Davison AJ, Blackbourn DJ. Kaposi's sarcoma-associated herpesvirus immune modulation: an overview. J Gen Virol. 2006;87(Pt 7):1781-804.

20. Fathimoghaddam F, Hedayati-Moghaddam MR, Bidkhori HR, Ahmadi S, Sima HR. The prevalence of hepatitis B antigen-positivity in the general population of Mashhad, Iran. Hepat Mon. 2011;11(5):346-50.

21. Vajdic CM, van Leeuwen MT. Cancer incidence and risk factors after solid organ transplantation. Int J Cancer. 2009;125(8):1747-54.

22. Grulich AE, van Leeuwen MT, Falster MO, Vajdic CM. Incidence of cancers in people with HIV/AIDS compared with immunosuppressed transplant recipients: a meta-analysis. Lancet. 2007;370(9581):59-67.

23. Cockfield SM, Preiksaitis JK, Jewell LD, Parfrey NA. Post-transplant lymphoproliferative disorder in renal allograft recipients. Clinical experience and risk factor analysis in a single center. Transplantation. 1993;56(1):88-96.

24. Cohen P. Infectious Diseases. 2nd ed: Mosby;2003.

25. Cattani P, Capuano M, Graffeo R, Ricci R, Cerimele F, Cerimele D, et al. Kaposi's sarcoma associated with previous human herpesvirus 8 infection in kidney transplant recipients. J Clin Microbiol. 2001;39(2):506-8.

26. Moore PS, Chang Y. Kaposi's sarcoma-associated herpesvirus immunoevasion and tumorigenesis: two sides of the same coin? Annu Rev Microbiol. 2003;57:609-39.

27. Marcelin AG, Calvez V, Dussaix E. KSHV after an organ transplant: should we screen? Curr Top Microbiol Immunol. 2007;312:245-62.

28. Einollahi B, Noorbala MM, Lessan Pezeshki M, Khatami MR, Simforoosh N, Firoozan A, et al. Incidence of postrenal transplantation malignancies: a report of two centers in Tehran, Iran. Trans- plant Proc. 2001;33(5):2812

29. Qunibi W, Al-Furayh O, Almeshari K, Lin SF, Sun R, Heston L, et al. Serologic association of human herpesvirus eight with posttransplant Kaposi's sarcoma in Saudi Arabia. Transplantation. 1998;65(4):583-5.

30. Jalilvand S, Shoja Z, Mokhtari-Azad T, Nategh R, Gharehbaghian A. Seroprevalence of Human herpesvirus 8 (HHV-8) and incidence of Kaposi's sarcoma in Iran. Infect Agent Cancer. 2011;6:5.

31. Frances C, Mouquet C, Calvez V. Human herpesvirus 8 and renal transplantation. N Engl J Med.1999;340(13):1045.

32. Bergallo M, Costa C, Margio S, Sidoti F, Re D, Segoloni GP, et al. Human herpes virus 8 infection in kidney transplant patients from an area of northwestern Italy (Piemonte region). Nephrol Dial Transplant. 2007;22(6):1757-61.

33. Rettig MB, Ma HJ, Vescio RA, Pold M, Schiller G, Belson D, et al Kaposi's sarcoma-associated herpesvirus infection of bone marrow dendritic cells from multiple myeloma patients. Science. 1997;276(5320):1851-4.

34. Wolf R, Brenner S, Ruocco V, Filioli FG. Isotopic response. Int J Dermatol. 1995;34(5):341-8.

35. Rosen HR. Hepatitis B and C in the liver transplant recipient: current understanding and treatment. Liver Transpl. 2001;7(11 Suppl 1):S87-98.

36. Naghibi O, Nazemian F, Naghibi M, Ali Javidi DB. Prognosis of HTLV-1 positive renal transplant recipients in Iran. Saudi J Kidney Dis Transpl.2011;22(4):670-4.

37. Brown RS. Hepatitis $\mathrm{C}$ and liver transplantation. Nature. 2005;436(7053):973-8.

38. Glicklich D, Thung SN, Kapoian T, Tellis V, Reinus JF. Comparison of clinical features and liver histology in hepatitis C-positive dialysis patients and renal transplant recipients. Am J Gastroenterol. 1999;94(1):159-63.

39. Fabrizi F, Lunghi G, Poordad FF, Martin P. Management of hepatitis B after renal transplantation: an update. $J$ Nephrol. 2002;15(2):113-22.

40. Nakamura N, Tamaru S, Ohshima K, Tanaka M, Arakaki Y, Miyauchi T. Prognosis of HTLV-I-positive renal transplant recipients. Transplant Proc. 2005;37(4):1779-82.

41. Khameneh ZR, Sepehrvand N, Masudi S, Taghizade-Afshari A. Seroprevalence of HTLV-1 among kidney graft recipients: a singlecenter study. Exp Clin Transplant. 2010;8(2):146-9. 